4th International Scientific Conference SEC-IASR 2019,

Galati, Romania, 7th - 8th June, 2019

\title{
The Exercises and Memory in the Secondary Schoolchildren
}

\author{
Damian PETCU, Diana Victoria GIDU \\ https://doi.org/10.18662/lumproc/sec-iasr2019/32
}

How to cite: Petcu, D., \& Gidu, D.V. (2020). The Exercises and Memory in the Secondary Schoolchildren. In S. Marin \& P. Moisescu (vol. eds.), Lumen Proceedings: Vol. 12. 4th International Scientific Conference SEC-LASR 2019 (pp. 302-308). Iasi, Romania: LUMEN Publishing House. https://doi.org/10.18662/lumproc/sec-iasr2019/32 


\title{
The Exercises and Memory in the Secondary Schoolchildren
}

\author{
Damian PETCU11, Diana Victoria GIDU2*
}

Abstract

The purpose of the work was to study if the exercise from physical education classhave or not positive effects in the memory of the secondary schoolchildren. For that, 97 schoolcbildren between 11 and 15 years old were tested. These tests aimed at determining the quality of memory by two types of tasks: a mathematical one, and a bumanistic one. The tests were performed both, before and after the physical education class. In order to assess the level of the physical demand, the heart rate was recorded during the class.

The effort from physical education class has no disruptive effect on the mathematical memory $[p<0.05]$. On the bumanistic type of memory the effects were null in boys and girls over 13 years old, while in girls under 13 years old, the effects were negative $[p<0.05]$.

Keywords: exercise from physical education class; mathematical and bumanistic memory; secondary schoolchildren.

${ }^{1}$ Ovidius University of Constanta, Constanta, Romania, petcudamian500@yahoo.com.

${ }^{2}$ Ovidius University of Constanta, Constanta, Romania, campiap@yahoo.com 


\section{Introduction}

Specialists, especially the teachers of physical education, often complain that some school directors, teachers of other subjects and parents consider physical education as a secondary subject where students just stretch their legs or hit a ball. Most of the other specialists still believe that physical effort has a negative impact on mental processes. In such cases, physical education teachers must be able to bring strong arguments about the benefits of physical education [8]. The biggest 'fault' that is brought to physical education - by non-specialists - is that the intellectual performance of pupils decreases after effort due to physical fatigue. What is less well known is that in physical activity, the brain requires different nerve centers than those used in intellectual activity. This makes a change in the activity of the various nervous centers resulting in their return to the initial stage.For example, an intellectual activity followed by a moderate physical effort leads to the return of nervous centers used in intellectual activity, the latter being able to perform a new activity with increased efficiency.

One of the mental processes with an important role in both intellectual and physical activity is memory. It represents the psychological process that ensures the acquirement of knowledge and skills and the possibility of their updating in different situations [3]. Memory is a necessary mental capacity without which life would be virtually impossible. Without memory, human would live in a continuous present: all the objects that would act upon him would seem to him absolutely new, unknown [9]. Russian psychophysiologist I.M., Secenov characterized memory as 'the fundamental condition of psychic life', 'the cornerstone of psychic life'[4].

Since memory is one of the mental processes that play an important role in physical activity, many researchers have studied the effects that physical effort has on it.

\section{Problem Statement}

E. Marinescu [3], JR. Thomas, DM Landers [5]have found that physical effort has positive effects in terms of the memory capacity of the subjects being tested. Y-A. Fery, A. Ferry [1] and V. Negrea, G. Musat [2] concluded that the extent to which physical effort affects short-term memory depends on the intensity of the effort and the size of the task to perform.Y. Zervas, A. Danis, V.Klissouras [7]have shown that the exhausting effort does not adversely affect short-term memory, both in trained and untrained persons; while T.Stockfelt(1972), quoted by Y. Zervas, 
N. Stambulova [8], has shown that the exhausting effort reduces the memory capacity as its intensity increases. PD.Tomporowski, NR. Ellis [6] concluded that the beneficial or harmful effects of physical effort on memory are motivated by the subject: trained persons regard the effort as a pleasant activity and are convinced that it produces beneficial effects; the untrained tend to see the physical effort as a stress and think it leads to a decrease in their performance.Also, GD. Gorbunov(1967)quoted by Y. Zervas, N. Stambulova [8] found that physical effort affects memory either positively or negatively, depending on the subject's ability to master the specific effort (experience).

From this brief review of the literature we studied, we cannot draw a unique conclusion as to the effect that physical effort has on memory, as the views aredivided. Also, no study has addressed the phenomenon from the perspective we would like to do: the effect of physical effort on pupils' memory at the class immediately following the physical education class. These are the starting points of this study.

\section{Research Questions/Aims of the research}

The purpose of the work was to study if the exercises from physical education class are or not positive effects in the memory of the secondary schoolchildren.

\section{ResearchMethods}

This study was conducted on 97 pupilsof N.Tonitza Middle School from Constanta, and consisted in testing the quality of attention before and after physical education class. The subjects had an average age of $13.43 \pm$ 1.14 years in girls $(n=51)$ and $13.69 \pm 1.19$ years in boys $(n=46)$. Both the quality of mathematical memory and the quality of humanistic memory were monitored.

For the mathematical task, the method of memorizing the figures was used; and for the humanistic task - the method of memorizing words. At the first type of mathematical test, the subjects were presented a board for 10 seconds, on which the figures from 0 to 9 were written in a certain order. Then in 60 seconds the pupils had to reproduce in writing the numbers, in the order in which they were written on the board.On the humanistic test, the subjects were orally presented 15 words, twice in a row. Then, in 60 seconds, they had to reproduce in writing as many of the words as they could, regardless of their order. 
Subjects were tested separately in grades. The pre-class tests were different from the post-class ones in terms of the words and figures used to remove the effect of learning the task. The working time for each test was monitored with a JEMIS electronic timer. The post-class tests were done 10 minutes after the end of the physical education class, that is after the break between the physical education class and the next class.

In order to highlight the physical demand of the subjects during their physical education class, they were monitored the heart rate [HR] after different actions. HR was monitored in 10 randomly selected subjects: 9 of them HR was monitored with the stethoscope, and one of them carried a POLAR heart rate monitor.

In statistical data processing we used the following parameters: arithmetic mean, standard deviation, mean difference. The minimal significance threshold was considered at $\mathrm{p}=0.05$.

\section{Findings}

Table 1. Average HR scores recorded during physical education class.

\begin{tabular}{ccccc}
\hline & $5^{\text {th }}$ grade & $6^{\text {th }}$ grade & $7^{\text {th }}$ grade & $8^{\text {th }}$ grade \\
\hline GIRLS & 139.16 & 163.12 & 148.12 & 156.12 \\
& \pm 13.17 & \pm 11.17 & \pm 9.11 & \pm 11.07 \\
BOYS & 133.16 & 159.15 & 152.12 & 152.16 \\
& \pm 15.05 & \pm 12.15 & \pm 14.03 & \pm 9.12 \\
\hline
\end{tabular}

Table 2: Average values obtained for mathematical memory task.

\begin{tabular}{ccccc|}
\hline & \multicolumn{2}{c}{ girls } & \multicolumn{2}{c|}{ boys } \\
& before class & after class & before class & after class \\
$5^{\text {th }}$ grade & $6.69 \pm$ & $8.07 \pm$ & $7.66 \pm$ & $8.66 \pm$ \\
& 2.65 & 2.39 & 3.08 & 2.00 \\
$6^{\text {th }}$ grade & $2.23 \pm$ & $3.69 \pm$ & $4.50 \pm$ & $7.00 \pm$ \\
& 1.92 & 2.78 & 3.25 & 3.50 \\
$7^{\text {th }}$ grade & $7.07 \pm$ & $8.07 \pm$ & $6.40 \pm$ & $8.60 \pm{ }^{\mathrm{a}}$ \\
& 2.39 & 2.46 & 3.86 & 2.50 \\
$8^{\text {th }}$ grade & $8.66 \pm$ & $8.75 \pm$ & $7.10 \pm$ & $9.70 \pm{ }^{\mathrm{b}}$ \\
& 1.72 & 2.41 & 3.47 & 0.94 \\
\hline
\end{tabular}

Legend: aSignificantly better than the testing before the class, $\mathrm{p}<0.02$

b Significantly better than the testing before the class, $\mathrm{p}<0.05$ 
Table 3: Average values obtained for humanistic memory task.

\begin{tabular}{ccccc}
\hline & \multicolumn{2}{c}{ girls } & \multicolumn{2}{c}{ boys } \\
& before class & after class & before class & after class \\
\hline $5^{\text {th }}$ grade & $8.00 \pm{ }^{\mathrm{a}}$ & $6.20 \pm$ & $9.44 \pm$ & $8.55 \pm$ \\
& 2.00 & 2.69 & 2.12 & 1.01 \\
$6^{\text {th }}$ grade & $8.61 \pm^{\mathrm{a}}$ & $7.69 \pm$ & $9.20 \pm$ & $8.90 \pm$ \\
& 1.93 & 1.75 & 2.09 & 1.59 \\
$7^{\text {th }}$ grade & $9.23 \pm$ & $8.69 \pm$ & $8.25 \pm$ & $8.25 \pm$ \\
& 1.16 & 1.10 & 1.35 & 2.00 \\
$8^{\text {th }}$ grade & $11.00 \pm$ & $10.22 \pm$ & $9.77 \pm$ & $10.77 \pm$ \\
& 1.32 & 1.56 & 1.92 & 2.94 \\
\hline
\end{tabular}

Legend: aSignificantly better than the testing after the class, $\mathrm{p}<0.05$

\section{Discussions}

As shown in Table 1, HR has values between $133.16 \pm 15.05 \mathrm{~b} / \mathrm{min}$ and $163.12 \pm 11.17 \mathrm{~b} / \mathrm{min}$, values that characterize a submaximal type of effort. Therefore, the demand for physical education was average. According to Y., Zervas, N. Stambulova [8], who demonstrated that the exhausting effort reduces the memory capacity as its intensity increases, the physical education effort should not cause the appearance of negative effects on pupils' memory.

The analysis of the results in Table 2 shows that the number of memorized figures increased significantly in the post-class test only in the $7^{\text {th }}$ and $8^{\text {th }}$ grade boys $(\mathrm{p}<0.05)$, while in the other subjects (fifth and sixth grade boys and all girls) the differences between the tests were not significant $(p>0.05)$. The conclusion that can be drawn is that the average intensity effort does not have a disturbing effect on mathematical memory; in the case of girls, the effect is null and in the case of boys, the effect is beneficial with aging. Other researchers [3.5] also found that physical effort has positive effects in terms of the memory capacity of the tested subjects.

Comparing the results by gender, separated within each grade (the girls to each other and the boys to each other), showed that the girls of the sixth grade achieved significantly lower scores than the girls from the other grades $(p<0.01)$, both in the before and after the class testing. I have not found a plausible explanation for this.

The differences were not significantly in boys ( $\mathrm{p}>0.05)$.

Regarding the humanistic memory task - word memorization - of Table 3, it is noticed that there are no significant differences between pre and post-hour tests in boys and girls with one exception. Girls of the 5th 
and 6th grade at which pre-class testing is significantly better than the postclass one. Thus, we could draw the following conclusion: the physical education effort has no disruptive effect on humanistic memory in boys and girls ages 13-15, while in girls aged less than 13 years these disturbing effects are significant.

Comparing the results by gender, separated within each grade (the girls to each other and the boys to each other) showed that the girls of the fifth grade had significantly lower scores than those of the 7th and 8th grades, and those of the 8th grade have significantly better scores than all the girls $(p<0.05)$. In boys, the 8th grade pupils had significantly better scores than those in the 7 th grade $(\mathrm{p}<0.05)$.

\section{Conclusions}

Based on the results of the study, we can draw the following conclusions:

1. The effort of the physical education class does not have a disruptive effect on the mathematical memory -memorizing figures.

2. Medium intensity effort adversely affects humanistic memory in girls under 13 years.

3. In girls over 13 years old and in boys, the humanistic memory memorizing of words - is not affected by the effort made during the physical education class.

\section{References}

Fery Y-A, Ferry A. Effect of physical exhaustion on cognitive functioning. Perceptual and Motor Skills.1997; 24: 291-298.

Negrea V, Musat G. Development of motor skills through movement games and contests to fifth grades. Science, Movement and Health. Sept. 2016: 16 (2, Supplement): 585-589.

Marinescu E. Influența educaţiei fizice asupra memoriei elevilor. Rev. de Ed. Fiz. şi Sp. 1977; 8:10-16.

Ribot T. Memoria si patologia ei.Bucuresti: Ed. Iri; 1998. pp. 67-78.

Thomas JR, Landers DM, et al. Exercise and cognitive function. Phys. Actv., Fitness and Health, Human Kinetics; 1994, pp. 521 - 529.

Tomporowski PD, Elli NR. Effects of exercise on cognitive processes: a review. Psychological Bulletin.1986; 3: 338-346.

Zervas Y, Danis A, Klissouras V. Influence of physical exertion on mental performance with referrence to training .Percept. and Mot. Skills.1991; 7:1215 1221. 
Damian PETCU \& ... | Lumen Proceedings 12 | SEC-IASR 2019

Zervas Y, Stambulova N. Phisycal activity and cognitive functioning. Psychology for physical educators, Human Kinetics; 1999, pp. 136-153.

Zlate M. Fundamentele psihologiei.Bucuresti: Ed. Pro Humanitate; 2000, pp. 43-48. 